\title{
Impact of presymptomatic genetic testing for familial amyotrophic lateral sclerosis
}

\author{
Joanna H. Fanos, PhD ${ }^{1,2}$, Susan Gronka, $R N^{3}$, Joanne Wuu, ScM ${ }^{3}$, Christine Stanislaw, MS , \\ Peter M. Andersen, MD, DMSc ${ }^{5}$, and Michael Benatar, MBChB, DPhil ${ }^{3}$
}

\begin{abstract}
Purpose: The Pre-familial Amyotrophic Lateral Sclerosis (Pre-fALS) study is a longitudinal study of individuals potentially at risk for developing familial amyotrophic lateral sclerosis. Our goals were to (1) explore participants' decisions of whether to learn results of presymptomatic testing or not; (2) understand the psychosocial impact of these decisions; and (3) assess preferences for receiving results by telephone or in person. Methods: The sample for this substudy comprised 20 participants drawn randomly from autosomal dominant mutant superoxide dismutase 1 families in the Pre-fALS study. Twenty participants completed a semistructured phone interview; prominent themes were identified and rated. Results: Fourteen participants chose to learn results; six had mutant superoxide dismutase 1 and eight had wild-type superoxide dismutase 1. Of the six who initially elected nondisclosure, three were reconsidering their decision. Regardless of the results and method of counseling, participants had adapted well, at least in the short term. Conclusion: We recommend that (1) those considering presymptomatic genetic testing should undergo professional counseling to help decide whether to learn results; (2) discussion should include the option of telephone genetic counseling for those without easy access to inperson counseling; and (3) those who initially decline to learn results should be offered the opportunity to learn their mutation status as their decision evolves. Genet Med 2011:13(4):342-348.
\end{abstract}

Key Words: familial amyotrophic lateral sclerosis, SOD1, presymptomatic, genetic testing, disclosure

A myotrophic lateral sclerosis (ALS) is a neurodegenerative disease characterized primarily by progressive loss of motor neurons with resulting weakness, wasting, and stiffness of both limb and bulbar muscles. ALS is familial in approximately $5-10 \%$ of cases. ${ }^{1-3}$ Inheritance may be either autosomal dominant or recessive. Mutations in $\mathrm{Cu} / \mathrm{Zn}$ superoxide dismutase (SOD) (mutant SOD1 [mtSOD1]) are the most common recognized cause of familial ALS (fALS), accounting for $12-23 \%$ of fALS cases. ${ }^{4-10}$ Most SOD1 mutations (with the exception of D90A in Europe) are dominantly inherited. More recently, mutations have been identified in the angiogenin, ${ }^{11} \mathrm{TDP} 43,{ }^{12}$ optineurin, ${ }^{13}$ and FUS genes, ${ }^{14,15}$ each accounting for another $1-5 \%$ of fALS cases. Knowledge of the specific genetic cause of fALS makes it possible to identify individuals at risk.

From the ${ }^{1}$ Department of Pediatrics, Dartmouth Medical School, Lebanon, New Hampshire; ${ }^{2}$ Stanford Center for Biomedical Ethics, Stanford, California; Departments of ${ }^{3}$ Neurology and ${ }^{4}$ Human Genetics, Emory University School of Medicine, Atlanta, Georgia; and ${ }^{5}$ Institute of Clinical Neuroscience, Umeå University, Sweden.

Michael Benatar, MBChB, DPhil, Department of Neurology, Emory University School of Medicine, Atlanta, GA 30322. E-mail: mbenatar@med.miami.edu.

Disclosure: The authors declare no conflict of interest.

Submitted for publication September 13, 2010.

Accepted for publication October 30, 2010.

Published online ahead of print January 31, 2011.

DOI: $10.1097 /$ GIM.0b013e318204d004
Few published studies have addressed concerns related to presymptomatic testing and disclosure of results in individuals at risk for fALS. ${ }^{16,17}$ Guidelines for presymptomatic testing in fALS have been proposed, ${ }^{18,19}$ but these guidelines have been based on experience in other conditions such as Huntington disease (HD) rather than experience with fALS. We have studied the process of presymptomatic genetic testing as part of the Pre-familial ALS (Pre-fALS) study, ${ }^{20}$ a prospective observational study of people potentially at risk for fALS. The rarity of fALS requires that participants be recruited from across North America, thereby increasing the logistical challenge of how best to provide genetic counseling for presymptomatic testing. As part of the pilot phase of Pre-fALS, we have sought to compare traditional in-person counseling (both pre- and post-test) with the approach of providing both pre- and post-test genetic counseling by telephone. In a qualitative substudy, 20 participants from mtSOD1 families were interviewed (by J.H.F.) about their experience. In this study, we report findings of this substudy, the goals of which were to (1) explore the basis for participants' decision of whether to learn the results of presymptomatic testing or not; (2) understand the psychosocial impact of the decision; and (3) assess attitudes toward receiving results by telephone or in person.

\section{MATERIALS AND METHODS}

\section{Study population}

\section{Pre-fALS}

The Pre-fALS study recruits individuals at risk for harboring a mutation in an ALS susceptibility gene. The larger study has thus far focused on families with mtSODI that is dominantly inherited with high penetrance, but efforts are currently underway to screen for families with mutations in other ALS susceptibility genes, such as TDP43 and FUS. In these families, an individual's probability for carrying the mutated gene is determined based on his/her kinship relatedness to a family member who has tested positive. Known carriers of a mutated gene are enrolled automatically for longitudinal follow-up. Individuals with a $50 \%$ chance of carrying the gene may participate in the larger study with the option of whether to learn the results of genetic testing or not. In the pilot phase of Pre-fALS, those who elected disclosure of genetic results were assigned randomly to receive counseling either in person or by telephone, with both provided by the same experienced board-certified genetic counselor (C.S.). Those who elected disclosure of results understood that they would be randomized to receive genetic counseling either by telephone or in person and that they could alternatively access genetic testing with traditional in-person genetic counseling through their health care provider. Counseling is performed before genetic testing (pretest counseling) and at the time that results are provided (post-test counseling). Participants who elect nondisclosure, as well as those who elect disclosure and are found to have $\mathrm{mtSOD1}$, are also enrolled in longitudinal follow-up and are then evaluated quarterly by telephone and 
annually in person. By contrast, participants who elect disclosure and are found to have wild-type SOD1 (wtSOD1) only receive telephone follow-up at 6 months. Although formal study evaluations occur at prespecified times, participants are encouraged to contact the study coordinator as needed. The Pre-fALS study team includes a neurologist, a research nurse, a genetic counselor, a statistician who is unblinded to all DNA results, and a psychiatrist available in the event of an untoward psychiatric consequence of study participation.

The larger Pre-fALS study was approved by the Institutional Review Board at Emory University School of Medicine, and written informed consent was obtained from all participants in accordance with the tenants of the Declaration of Helsinki. ${ }^{21}$ Pre-fALS is covered by a National Institutes of Health Certificate of Confidentiality, which provides protection against forced disclosure of confidential information. ${ }^{22}$

\section{Substudy}

The sample for this substudy included 20 individuals randomly drawn from the larger Pre-fALS study using a computer generated sequence. All participants in this substudy had already undergone genetic counseling and testing as part of the larger Pre-fALS study. The Committee for the Protection of Human Subjects at Dartmouth Medical School approved the substudy, and subjects provided additional verbal consent before being interviewed.

\section{Genetic testing}

Testing for mtSOD1 in the Pre-fALS study was performed in the ALS research laboratory at Umeå University (by P.M.A.). The laboratory has been performing SODl genetic testing since 1993. DNA analyses were performed as described. ${ }^{23}$ Permission was obtained from the Food and Drug Administration to disclose results of genetic testing performed in a non-Clinical Laboratory Improvement Amendments-certified laboratory, with the provision that the informed consent document explicitly states that genetic testing was performed in a research laboratory.

\section{Qualitative analysis}

Participants were interviewed individually over the telephone for approximately 1 hour. Phone interviews were conducted by J.H.F., tape recorded, and transcribed verbatim. Interviews began with open-ended questions and moved to specific probes if material was not forthcoming. Participants were questioned about their decision of whether to learn results of genetic testing or not, the psychosocial impact of their decision, and their attitudes toward receiving results by telephone or in person at Emory. Using content analysis, ${ }^{24}$ major themes emerged, reflecting important aspects of psychosocial adaptation; these were coded by J.H.F. Three interviews were randomly selected and given to an outside rater. When a suitable level of reliability was attained, the outside rater coded the remaining 17 interviews. Interrater reliability was obtained on all thematic categories and yielded an overall kappa of 0.99 .

\section{RESULTS}

\section{Sample characteristics of the substudy}

Twenty participants ( 15 women and 5 men) were interviewed from 17 autosomal dominant families with high penetrance for ALS associated with five SOD1 gene mutations ( $A 4 \mathrm{~V}, I 113 \mathrm{~T}$, $D 90 A, L 106 V$, and $L 144 F$ ). Participants ranged in age from 27 to 66 years (median, 47). Two were single, 12 married, 5 divorced, and 1 separated (Table 1). Median education was a college degree; mean household income \$97,235. All were white and born in the United States, although originally of European descent. Fifteen individuals had biological offspring (one of these had one biological child and one adopted); one individual had two adopted children. Four participants had no children. Median number of offspring was two. Median age of biological offspring was 21 years (range, 4-43). Seven participants had one or more children younger than 18 years. Of these seven, five had at least one or more adolescents. Eighteen participants had lost a parent to ALS (12 lost a father and 6 a mother). Two of these had experienced the loss of a parent (their father) before age 21 years (one was 8 years at the time and the other 20 years). Five had lost a sibling to ALS during adulthood; two had a sister living with ALS. Participants have thus far been followed up for a median of 18 months (range, 7-29) since the time of enrollment, genetic testing, and communication of results.

\section{Attitudes toward learning results of presymptomatic testing for an SOD1 mutation}

Of the 20 participants in this substudy, $14(70 \%)$ had chosen to learn results; six chose not to know. This percentage is similar to that of participants in the Pre-fALS study, in which $77 \%$ have opted thus far for disclosure of genetic results (unpublished data). These figures are somewhat higher than the

Table 1 Major reasons for decision regarding disclosure of genetic results

\begin{tabular}{|c|c|c|c|}
\hline \multicolumn{2}{|c|}{ Disclosure: Decision to learn genetic results $(n=14)$} & \multicolumn{2}{|c|}{ Nondisclosure: Decision not to learn genetic results $(n=6)$} \\
\hline Reason & Frequency $^{a}$ & Reason & Frequency $^{a}$ \\
\hline $\begin{array}{l}\text { Desire to obviate need for children to undergo } \\
\text { genetic testing }\end{array}$ & 8 & Belief that gene status is $\mathrm{mtSODI}$ & 6 \\
\hline Desire to reduce anxiety/ambiguity & 5 & Fear or worry about every symptom if harbor $\mathrm{mtSOD1}$ & 5 \\
\hline \multirow[t]{4}{*}{ Desire to make appropriate lifestyle decisions } & 4 & Desire to maintain hope & 1 \\
\hline & & Desire to spare relatives worry & 1 \\
\hline & & Fear of regretting learning results & 1 \\
\hline & & Fear of "survival guilt" if found not to have mtSOD1 & 1 \\
\hline
\end{tabular}

${ }^{a}$ Some participants cited more than one reason.

$\mathrm{mtSOD1}$, mutant superoxide dismutase 1 . 
$52-64 \%$ who expressed a preference for disclosure of genetic results based on an earlier survey of attitudes toward genetic testing for fALS. ${ }^{25}$

\section{Decision to learn testing results}

During the semistructured interview, all participants were asked about their decision to learn results. Major reasons included freedom from living with ambiguity; reduction of anxiety; desire to make appropriate lifestyle decisions, including taking preventive measures; and willingness to be tested, so that, despite being in a family known to have a mutation in the SOD1 gene, they might obviate the need for their children to be tested if they were found to have wtSOD1.

One participant, tired of living with ambiguity, sought control of her life. She reported "I have always felt [that] to know was a better case scenario for me than to be in the dark and wonder, what if?" Another reported that she chose to learn results because she was "going crazy not knowing." One man, before participation in Pre-fALS, had moved with his wife from their multistory home to a single-level dwelling in case he had the mutation. He explained "One of our decisions to buy this house was if I were ever going to end up in a wheelchair, it would be easy to move me around on one floor." By learning whether he had the mutation, they could decide whether or how to arrange other aspects of their lives. As part of lifestyle planning, several wanted to know, so that they could take active measures to remain as healthy as possible, with plans to improve food choices, increase antioxidant use, etc.

Children were a major theme in seeking testing and learning results. Of the 11 participants who had their own biological offspring and chose to learn results, eight cited their children as a major reason. One participant explained that she did not want her children and grandchildren to live with the uncertainty she had for 20 years:

"It was a big burden on my shoulder. I thought if I had a bad report, then ... it was up to me to sacrifice myself [and undergo testing] for my children."

One participant decided that she would be tested but would keep results to herself for now. She thought that there should be documentation of her mutation status if anything should happen to her unexpectedly (e.g., an accident), then her children could make their own decisions about testing; or if she had the mutation and a cure was found, she would inform them of her status at that time. Another participant felt that he should be tested to help his own family-even if he did have the mutation, researchers might find out through him how not to treat it - and be able to "cross one more thing off the list." He traveled to Emory for in-person counseling without telling his adult offspring and called a family meeting immediately on his return. When he told his family that the test results were negative, his adult children expressed their relief:

"Number one, they don't have to witness their parents deteriorate. The other is, they don't have this cloud over their head wondering-every little muscle twitch or ache or pain-Is this the beginning of the end?"

Another participant explained that he probably would not have learned results if he had not had children. Prior to being tested, his two adult offspring had had lengthy discussions with him, and both offered to be tested. However, he believed that it was unfair for them to have to "take that step" but that it was his responsibility. He said "I just had to do it for them." He was delighted to tell them that he did not have the gene and be able to say "Hey kids, guess what?"

\section{Decision not to learn the results of testing}

Six participants had chosen not to learn results at the time of the interview; all had believed that they carried a mutation in the SOD1 gene. By contrast, only half $(7 / 14)$ of those who chose to learn results believed that they carried the mutation. For some, their belief was based on the high prevalence of the disorder in their families. Individuals heard the story of their grandparents, aunts, or uncles and watched their own parent succumb to ALS.

Additional reasons for deciding not to learn results included a fear that they would worry about every symptom, a wish to maintain hope, the desire to spare relatives worry if they tested positive for mtSOD1, a fear of regretting having learned results, and concern about feeling guilty if negative. One man thought it would not be good for him to know that he definitely carried the mutation, fearing that he would be beset with concerns every time he had a potential symptom. He believed that "not knowing just kind of gives me that hope. I think it's more than likely that I will get it. You get out of bed and your leg hurts-well, here it is."

One daughter decided not to learn results because the finding of mtSODl would be too difficult for her mother, who had already been involved with the care of her husband (the participant's father), to handle. She believed that her daughter, who had been distraught when she lost her grandfather, would have a difficult time with it as well. In addition, she worried that, despite her belief that she could handle the news, good or bad, she might find out otherwise:

"I leaned toward I don't want to know. I don't want to think I can handle it and get there and then feel, 'I really don't want this information."”

One woman who had lost her sister to ALS was concerned that if she learned that she had wtSOD1, she would feel guilty and wonder "Why are you more special than your sibling?" She stated that if she had not already had children, she would have wanted to know her results, so that if she had mtSOD1 she would not have offspring: "To me, it has to stop being passed on somewhere." Another participant struggled with the thought that her sister had several children and she had only one, so she would feel guilty if found not to have the gene mutation:

"The idea of somebody getting it that has 3 kids just really bothers me. So if I could get it, and it not go to her, I think I could live with that."

\section{Changing mind about learning results}

Of the six participants who initially decided not to learn results, three were rethinking their decision. Three believed that if they had more counseling before making that choice, they might have taken a different stance. They had come to their original decision on their own or with the help of friends or family but now that they were part of the Pre-fALS study, they were revisiting their choice.

\section{Psychological impact of learning wtSOD1 results}

For those eight receiving wtSOD1 results, two (25\%) were accurate in believing they would have wtSOD1, three had believed that they would have mtSOD1, and three had no prior beliefs. Those who learned that they had wtSOD1 were relieved but cited that their lifestyle had not changed, except that the concern was no longer on their minds; some expressed relief 
that their children and grandchildren could now live their lives free from this issue. Some had contemplated potential changes in their life that they would make had they learned they had mtSOD1 and now were able to resume their former lives.

Those three participants who had no preexisting "hunches" had not made any major changes but mentioned a few improvements in their lives. One woman who had no prior beliefs reported that the results had allowed her to appreciate life more fully and is mending an important relationship. One man, found to have wtSOD1, did not know what his results would be but was tired of going back and forth in his beliefs. He recalled injuring a muscle when his mother was diagnosed with the disease and before learning his status. Healing was slow, and his first thought was "Oh man, is the muscle getting weaker?" Now he finds "mornings are brighter" and looks forward to being able to see his children have children of their own:

"Our state has this mega-million lottery. My wife and I kid about it all the time. 'I've got to get my ticketmaybe we'll hit the lottery.' One of us will say that part and the other one will always say, 'I think we already did." "'

One man, having no prior beliefs, reported that he did not have "any massive celebrations." He does look back, however, and thinks how it could have been, reporting: "I do check myself every once in a while, just to be grateful." Those who thought that they would have the mutation and received wtSOD1 results reacted with tremendous relief at the time. Surprisingly, often their joy was difficult to maintain. For example, one woman, who thought she would have mtSOD1 since she has symptoms, "dared" to think about what it would be like to receive wtSOD1 results, anticipating that it would be an "amazing" relief. She did find it to be a wonderful feeling but difficult to sustain. Occasionally, she located the letter in which her results were stated, to remind herself of her good fortune:

"I still go back and read the letter that I was sent every now and then. But it's not been as joyful, in a sustained way, as I would have anticipated."

Ironically, one woman, shocked that she did not have the mutation, reported that she had accepted that she would not live another 10 years. Now, she had to "rethink" the rest of her life, explaining that she had no retirement. "It actually had been harder dealing with the fact that I am going to be here longer."

\section{Guilt and reluctance to disclose results to relatives after wtSOD1 results}

Of the eight participants who chose to receive results and learned that they had wtSOD1, five were rated as having moderate guilt over being spared. However, they had, for the most part, resolved these feelings over time. One man had lost his younger brother to ALS. He struggled to understand, "Why him, not me?" He resolved his guilty feelings by telling himself that as there was nothing he could do about it, it was important for him to go on with his own life. One woman, whose father had died of the illness, felt both relieved and guilty when she learned her wtSOD1 results. She had resolved her guilt by researching the genealogy of her family. One woman, who received good news of wtSOD1 results, was reluctant to disclose results to her siblings, fearing that it could alter their relationships and that they would believe that their 50/50 chances had increased. She did not reveal her status until her family finally convinced her to share her results with them. One man, similarly concerned that his wtSOD1 results would affect his relationship with other relatives, explained to his adult offspring that his results were to be kept confidential: "We just can't discuss it. It'll be something we only talk about here."

\section{Psychological impact of learning $\mathrm{mtSOD1}$ results}

Of those six who heard that they had mtSOD1, four had correctly believed that they carried the mutation (67\%), one believed she did not, and one had no prior beliefs. One woman believed that she would have wtSOD1 as she had already suffered emotionally difficult times in her life and hoped she would escape this fate. She explained:

"I know it's genetic, but when it came down to me, I'd already been through a lot. Can one more thing be piled on me? Apparently it could."

Some had heard that fALS could "skip a generation." The diagnosis of ALS in one's generation was, therefore, particularly worrisome. One man had hoped that he might be spared since he was the first of his generation to be tested but, unfortunately, had mtSOD1. He reported:

"To find out that it was going to this generation bothered me more than anything. We were all hoping that it was done with the older generation, and that would be the end of it. But it obviously is not."

The majority $(5 / 6)$ of those who learned that they had the mutation reported changes in their lives, ultimately for the better. One woman reported a clearer perspective on priorities. Now proactive about her health, she believed that knowing was more "a step up than a knock down." One man had lost his father to ALS during his childhood. After learning that he had the mutation, he made "pretty dramatic" changes, including leaving a job in which he had been considerably invested and moving home to be with his family. He has also changed his view on marriage. He had always hoped to get married but having experienced ALS "first hand," he believed that marriage for him "may not be the best way to go." Despite an appreciation of the seriousness of his genetic result, he felt grateful that the opportunity was presented:

"I definitely am happy I know my results and feel prepared for what could possibly happen. I don't have any regrets."

Three had received news of their mtSOD1 status by telephone. One woman, despite feeling that she likely had the mutation, reported having felt frantic for the following week, deciding ramifications for health care and insurance, and how to tell her son. She had been alone when receiving the news. After talking with friends and family, she has come to accept her status. She reported that she had been taking better care of herself, eating healthier foods, and establishing different priorities. She did not believe that it would have made any difference had she received the results in person but wished that she had a support person in place at the time of the phone call. Feeling grateful, she explained, "I feel now in some ways it's a gift to know that my time is not infinite." Another woman found the news she received by telephone devastating at first but did not believe that she would have been in less distress receiving results in person. Although upset, she did not have the time "to crumble or feel sorry for myself." She made no major changes, although she tried to have a healthier diet, rich in antioxidants, and continued her exercise program. She appreciated her changed perspective, 
explaining: "Earlier I'd worry about my laptop; I don't worry about those things anymore." She recalled a statement made by a member of the Pre-fALS team that she found helpful in calming a relative:

" 'Nothing has changed. You have the gene, but nothing else has changed.' I think for us that was very reassuring."

Another woman reported that, after her father's death from ALS, she had been preoccupied wondering if she had the mutation. On learning her mtSOD1 results by telephone, she was in significant distress for about a month. It was not until she went to Emory for her baseline visit that she was able to feel better. She told herself that she could continue being miserable or she could choose to look at her situation in a different way. She decided that there had been no real change in her view of herself:

"I've [had the SOD mutation] since the day my parents conceived me in my mom's womb. So I had to change the way that I thought about it."

When asked whether she would make the same decision to learn results again, she replied "Absolutely-I don't think about it all day long now; it has taken a huge weight off me." Our participants were sophisticated about ALS as they had seen it all too often in their own families. For some, learning they had the mutation escalated into concerns of having ALS, including end stage issues such as where to find good palliative care or how to plan their funeral. Several contemplated ways in which they could ensure that they could end their lives at the point immediately before they became completely dependent on others. As one man explained:

"I saw what my mom went through, and I wouldn't burden others. I would probably do something before I became completely immobilized. I'm trying to . . . what is the least painful method-maybe exhaust fumes in the garage."

\section{Attitudes toward receiving results in person versus by telephone}

The larger Pre-fALS study had randomized participants who wished to learn results into groups receiving results in person or by telephone. In this substudy, of the 14 receiving results, seven did so in person and seven by telephone. In both groups, four had wtSOD1 and three mtSOD1. Overall, participants were comfortable with the group into which they had been randomized. Three of those receiving results by telephone appeared to have had the most difficulty in accepting the news. One felt upset for about a month; on going to the study center for her baseline visit, she was able to feel "part of a bigger picture." The other two felt panicky for about a week but adapted after talking with friends and family. When asked their preference for receiving results, they felt it would have been no easier to learn results in person.

Substudy participants were asked about their personal preference had they been able to choose the modality of counseling (in person or by telephone). Of the 14 (six mtSOD1) who chose to learn results, seven would have preferred to learn results in person, four by telephone, and three had no preference. Of those six found to have mtSOD1, three would have preferred inperson counseling, one telephone counseling, and two expressed no preference. Those who expressed a preference for in-person counseling stated the following advantages: (1) it is preferable to have face-to-face contact for such a highly personal topic; (2) the Pre-fALS team was a motivating forcebeing part of research was empowering; and (3) being on-site allowed questions to be answered immediately by medical professionals. One woman explained:

"This disease is really personal to us, and so personal that it's killing all of our family members. I never felt better about it until I went there."

The four participants who preferred telephone counseling stated the following advantages: (1) travel could be avoided, because it could be inconvenient and stressful; (2) individuals sought by participants for emotional support were readily accessible at home; and (3) one could avoid being emotionally vulnerable in the presence of medical professionals in an institutional setting, which could be rather impersonal. Those who preferred receiving results by telephone recommended a follow-up call within a few days to allow time to recover from the initial shock and to think of questions. One participant stated:

"Once I hung up off the phone, I had all these questions going through my head-it took a few hours to sink in."

The three participants who had no counseling preference saw advantages and disadvantages of both delivery methods. Some explained that the choice of delivery would not influence test results. One suggested that participants should be offered the choice of learning the results in person or over telephone.

\section{DISCUSSION}

\section{Decision to learn results is an evolving process}

For our 20 participants, the decision to get tested and whether to learn results or not was not fixed but rather a fluid process, similar to HD. ${ }^{26,27}$ Many believed that more counseling might have altered their decision. Multiple encounters with the PrefALS research team prompted some who initially declined learning results to find the option of knowing their status more compelling.

\section{Adapting to mtSOD1 or wtSOD1 results}

Experience from the HD literature suggests that family members who have tested negative for mutations in the Huntingtin gene have had difficulty coping with this favorable result. ${ }^{28,29}$ Williams et al., ${ }^{28}$ for example, described the process in which individuals who received negative results from testing in HD had to work to redefine themselves as no longer at risk. In our sample, one individual had considerable difficulty with this, having lived essentially unprepared for the possibility of a long and healthy life. A few others had to remind themselves of having wtSOD1; one woman occasionally reread the letter to reexperience the joy she felt on initial receipt. In general, most who received wtSOD 1 results had returned to their lives without much difficulty.

Initial concerns about serious adverse events such as suicide among those who were found to harbor mutations in the Huntingtin gene have proven to be unfounded, at least in the short term. $^{30-32}$ Similarly, disclosure of apolipoprotein E genotype for risk of Alzheimer disease has not resulted in significant short-term emotional distress. ${ }^{33}$ In our sample, we similarly found no indication of serious suicidal risk. Although one woman had fleeting thoughts on initial news of mtSODl status, they were not dwelled on but part of a myriad of other intense but transient emotional responses. Receiving news of mtSOD1 status had been extremely unsettling for a number of partici- 
pants in the Pre-fALS study, but nearly all had come to terms with the results within a relatively short time.

Several Pre-fALS subjects who learned that they carried the mtSOD1 gene comforted themselves with the thought that, although they had the mutation, "Nothing has changed." This may be similar to $\mathrm{HD}$, in which carriers make various efforts to minimize the negative effects of test results. ${ }^{34}$ Many were grateful to the nurse (S.G.), who read from the consent form: "any risk you may have will not change if you decide to participate in the study." The fact that they found solace in knowing that they always had the mutation is significant. Although there is, one might argue, a change in their perceived or known risk for fALS, participants chose to focus on the lack of change in actual risk. Whether this adaptation withstands the test of time, or whether, as in HD, ${ }^{35}$ individuals become more distressed as they approach the age at which relatives succumbed to the disease, needs to be explored; although one important difference between fALS and HD is that age of onset of fALS cannot be predicted with any degree of certainty. Identification of oneself as having a deleterious genetic mutation is a potentially significant threat to the sense of self. Successful adaptation depends on efforts to manage the threat. That some were able to interpret $\mathrm{mtSOD} 1$ status as reflecting no change is highly adaptable and allows them to find comfort in a situation fraught with peril. These efforts could be seen as part of an effective strategy of self-regulation. These findings are similar to an earlier study in fALS, ${ }^{17}$ in which many were able to live fully, not dwelling on thoughts of ALS. It may be that individuals are thoughtfully assessing their psychological ability to handle receiving "bad news" and choosing accordingly. Evidence from HD has similarly suggested that self-selection may explain why predictive testing for HD may not be as problematic as predicted. ${ }^{36-38}$

\section{Method of disclosure of results: In person or by telephone}

The medical community has for a long time assumed that it is preferable to communicate difficult news in person. Physicians themselves generally feel most comfortable delivering such news in their offices or clinics, to allow access to nonverbal communication of distress. In our study, participants challenged this long-cherished view. Several suggested that, as many individuals held disparate — but strongly felt — views, the ideal would be to allow the individual to make his or her own choice. In a recent study of $B R C A 1 / 2$ genetic testing, Baumanis et al. ${ }^{39}$ reported that patients who were given a choice of receiving results in person or by telephone reported significantly higher satisfaction than those who were not; in addition, patients who were given a choice of delivery method were more likely to select disclosure by telephone. There are, however, potential risks to telephone disclosure: first, it is possible that individuals who choose to learn results by telephone may not predict adequately the range of their emotional reaction. Second, one may be stoic at the time of the phone call but experience the full psychological impact hours later, with no institutional support readily available. As more centers disclose results from presymptomatic testing for fALS and other genetic disorders, there is increasing need to establish the best practice of delivery. We found that telephone or in-person counseling and/or disclosure may be appropriate, depending on individual preferences. It is important that the participant and counselor discuss the advantages and disadvantages of each approach, through a predecision counseling session.

\section{Grieving multiple losses}

Individuals who struggle with the possibility that they may have the mutation have already experienced the devastating illness and death of multiple relatives - in one case as many as 25-in many generations. Most of the substudy participants had already lost a parent, and many have been intimately involved as the primary caretaker of a loved one experiencing the relentless progression of the disease. They have grown up in families in which the preponderance of this medical history has been noted; many have lived for years with the assumption that they probably had the mutation. Unlike an earlier study, ${ }^{17}$ most of our 20 participants had been spared the trauma of parental death in early childhood or adolescence, with its predictable posttraumatic symptoms. ${ }^{40}$ On the other had, our participants were overwhelmed with grieving multiple losses. As one woman, carrying an SOD1 mutation, explained:

“In families like ours, someone dies, and then you're passing on the wheelchair to the next person who is going to die. We never get a chance to grieve."

A few found relief in creative ways to honor their lost parent. One woman is writing a book to tell the story of ALS and her family. One participant, acutely grieving the loss of her father, sent photographs to J.H.F., so that we might bear witness to how handsome and vital he had been before the development of ALS, and what a wonderful father he was, immortalized in a poignant photo in which he holds the participant, then a small child, in his arms. Although medical professionals may assume that psychological distress is linked to $\mathrm{mtSOD1}$ status, it is important to discern whether the distress is due to carrying the mutation or unresolved mourning of loved ones.

A coping strategy for some who had the mutation was to plan far beyond the advent of any symptom or diagnosis. Resources need to be identified-including in their own communitiesthat could provide help in thinking through such distant issues. Most institutions (e.g., ALS centers) are charged with helping those who already have the disorder, not those at risk. National foundations and online support groups may help provide both emotional and practical support. With the growth of palliative care in the United States, individuals struggling with such difficult decisions should be able to locate institutional support.

\section{RECOMMENDATIONS}

Although presymptomatic genetic testing for carrier status among healthy at risk individuals in families associated with an SOD1 mutation has been available for some time, optimum practices for communicating these results have not been established. On the basis of our substudy, we recommend:

1. Individuals considering presymptomatic genetic testing, whether as part of a research study or not, should undergo professional counseling to help them decide whether they really wish to learn the results.

2. An important part of the counseling process may be to discuss whether disclosure and discussion of results should take place in person or over telephone.

3. Presymptomatic individuals should be offered the opportunity to learn results as their decision evolves. Those who initially chose not to learn results of genetic testing may change their minds, at which time they should undergo genetic counseling before results are disclosed. Similarly, individuals who choose to learn results may change their 
minds after receiving pretest counseling and forego post-test counseling, at which time results would have been disclosed.

4. Long-term follow-up is needed to determine whether the short-term positive reactions/adaptations persist.

\section{ACKNOWLEDGMENTS}

This study was funded by Grants from the Muscular Dystrophy Association (Grant no. 4365) and the Woodruff Health Sciences Center at Emory University, the Swedish Brain Research Foundation, the Hållstens Brain Research Foundation, the Swedish Medical Society, and the Swedish association for the neurologically disabled. This work was also supported in part by PHS Grant (UL1 RR025008, KL2 RR025009, or TL1 RR025010) from the Clinical and Translational Science Award program, National Institutes of Health, National Center for Research Resources. The authors are grateful to the families and individuals who participated in this research.

\section{REFERENCES}

1. Haverkamp LJ, Appel V, Appel SH. Natural history of amyotrophic lateral sclerosis in a database population. Validation of a scoring system and a model for survival prediction. Brain 1995;118:707-719.

2. Li TM, Alberman E, Swash M. Comparison of sporadic and familial disease amongst 580 cases of motor neuron disease. J Neurol Neurosurg Psychiatry 1988;51:778-784.

3. Chio A, Traynor BJ, Lombardo F, et al. Prevalence of SOD1 mutations in the Italian ALS population. Neurology 2008;70:533-537.

4. Andersen P, Nilsson P, Keranen M, et al. Phenotypic heterogeneity in motor neuron disease patients with $\mathrm{CuZn}$ superoxide dismutase mutations in Scandinavia. Brain 1997;120:1723-1737.

5. Boukaftane Y, Khoris J, Moulard B, et al. Identification of six novel SOD1 gene mutations in familial amyotrophic lateral sclerosis. Can J Neurol Sci 1998;25:192-196.

6. Cudkowicz ME, McKenna-Yasek D, Sapp PE, et al. Epidemiology of mutations in superoxide dismutase in amyotrophic lateral sclerosis. Ann Neurol 1997;41:210-221.

7. Garcia-Redondo A, Bustos F, Juan YSB, et al. Molecular analysis of the superoxide dismutase 1 gene in Spanish patients with sporadic or familial amyotrophic lateral sclerosis. Muscle Nerve 2002;26:274-278.

8. Jones CT, Swingler RJ, Simpson SA, Brock DJ. Superoxide dismutase mutations in an unselected cohort of Scottish amyotrophic lateral sclerosis patients. J Med Genet 1995;32:290-292.

9. Orrell RW, Habgood JJ, Gardiner I, et al. Clinical and functional investigation of 10 missense mutations and a novel frameshift insertion mutation of the gene for copper-zinc superoxide dismutase in UK families with amyotrophic lateral sclerosis. Neurology 1997;48:746-751.

10. Shaw CE, Enayat ZE, Chioza BA, et al. Mutations in all five exons of SOD-1 may cause ALS. Ann Neurol 1998;43:390-394.

11. Greenway MJ, Andersen PM, Russ C, et al. ANG muttations segregtate with familial and 'sporadic' amyotrophic lateral sclerosis. Nat Genet 2006;38: 411-413.

2. Van Deerlin VM, Leverenz JB, Bekris LM, et al. TARDBP mutations in amyotrophic lateral sclerosis with TDP-43 neuropathology: a genetic and histopathological analysis. Lancet Neurol 2008;7:409-416.

13. Maruyama H, Morino H, Izumi Y, et al. Mutations of optineurin in amyotrophic lateral sclerosis. Nature 2010;465:223-226.

14. Vance C, Rogelj B, Hortobagyi T, et al. Mutations in FUS, an RNA processing protein, cause familial amyotrophic lateral sclerosis type 6 . Science 2009;323:1208-1211.

15. Kwiatkowski T, Bosco DA, Lecler AL, et al. Mutations in the FUS/TLS gene on chromosome 16 cause familial amyotrophic lateral sclerosis. Science 2009;323:1205-1208.
16. de Belleroche J, Orrell R, King A. Familial amyotrophic lateral sclerosis/ motor neurone disease (fALS): a review of current developments. $J$ Med Genet 1995;32:841-847.

17. Fanos JH, Gelinas D, Miller R. You have shown me my end: attitudes toward presymptomatic testing for familial amyotrophic lateral sclerosis. Am J Med Genet 2004;129A:248-253.

18. Andersen PM, Borasio GD, Dengler R, et al. EFNS task force on management of amyotrophic lateral sclerosis: guidelines for diagnosing and clinical care of patients and relatives. Eur J Neurol 2005;12:921-938.

19. Andersen PM, Borasio GD, Dengler R, et al. Good practice in the management of amyotrophic lateral sclerosis: clinical guidelines. An evidence-based review with good practice points. EALSC Working Group. Amyotroph Lateral Scler 2007;8:195-213.

20. The Pre-Familial Amyotrophic Lateral Sclerosis (Pre-fALS) Study. Available at: http://clinicaltrials.gov/ct2/show/NCT00317616?term_ benatar\&rank_4. Accessed November 23, 2010.

21. World Medical Organization. Declaration of Helsinki. BMJ 1996;313:14481449.

22. Certificate of Confidentiality Kiosk. Available at: http://grants.nih.gov/ grants/policy/coc/. Accessed November 23, 2010.

23. Felbecker A, Camu W, Valdmanis PN, et al. Four familial ALS pedigrees discordant for two SOD1 mutations: are all SOD1 mutations pathogenic? J Neurol Neurosurg Psychiatry 2010;81:572-577.

24. Weiss R. Learning from strangers. New York: Macmillan, 1994.

25. Benatar M, Polak M, Kaplan S, Glass J. Preventing familial amyotrophic lateral sclerosis: is a clinical trial feasible? J Neurol Sci 2006;251:3-9.

26. Quaid KA, Sims SL, Swenson MM, et al. Living at risk: concealing risk and preserving hope in Huntington disease. J Genet Counsel 2008;17:117-128.

27. Taylor SD. Predictive genetic test decisions for Huntington disease: elucidating the test/no test dichotomy. J Health Psychol 2005;10:597-612.

28. Williams JK, Schutte DL, Evers C, Holkup PA. Redefinition: coping with normal results from predictive gene testing for neurodegenerative disorders. Res Nurs Health 2000;23:260-269.

29. Gargiulo M, Lejeune S, Tanguy ML, et al. Long-term outcome of presymptomatic testing in Huntington disease. Eur J Hum Genet 2009;17:165-171.

30. Lawson K, Wiggins S, Green T, et. al. Adverse psychological events occurring in the first year after predictive testing for Huntington's disease. The Canadian Collaborative Study Predictive Testing. J Med Genet 1996; 33:856-862.

31. Wiggins S, Green T, Adam S, Hayden MR. A long term (ca 5 years) prospective assessment of psychological consequences of predictive testing for Huntington disease (HD). Am J Hum Genet 1996;59:A7.

32. Tibben A, Duivenvoorden HJ, Niermeijer MF, et al. Psychological effects of presymptomatic DNA testing for Huntington's disease in the Dutch program. Psychosom Med 1994;56:526-532.

33. Green RC, Roberts JS, Cupples LA, et al. Disclosure of APOE genotype for risk of Alzheimer's disease. N Engl J Med 2009;361:245-254.

34. Decruyenaere M, Evers-Kiebooms G, Boogaerts A, et al. Prediction of psychological functioning one year after the predictive test for Huntington's disease and impact of the test result on reproductive decision making. J Med Genet 1996;33:737-743.

35. Tinman R, Roos R, Maat-Kievit A, Tibben A. Adverse effects of predictive testing for Huntington disease underestimated: long-term effects 7-10 years after the test. Health Psychol 2004;23:189-197.

36. Decruyenaere M, Evers-Kiebooms G, Cloostermans T, et al. Psychological distress in the 5-year period after predictive testing for Huntington's disease. Eur J Hum Genet 2003;11:30-38.

37. Kessler S. Predictive testing for Huntington's disease: a psychologist's view. Am J Med Genet 1994;54:161-166.

38. Tibben A, Roos RA, Niermeijer MF. Psychological consequences of presymptomatic testing for Huntington's disease. Lancet 1997;349:809.

39. Baumanis L, Evans JP, Callanan N, Susswein LR. Telephoned BRCA1/2 genetic test results: prevalence, practice, and patient satisfaction. $J$ Genet Couns 2009; 18:447-463.

40. American Psychiatric Association. Diagnostic and statistical manual of mental disorders, 4th ed. Washington, DC: American Psychiatric Association, 1994 